\title{
Radiographic Analysis of Posterior Airway Variation, Gonial Angle, Mandibular Length and Facial Height in Patients Submitted to Vertical Mandible Osteotomy
}

\author{
Idiberto José Zotarelli Filho ${ }^{1,2}$, Elias Naim Kassis ${ }^{1,2}$, Diego César Marques $^{2}$, Luciana Fortes \\ Tosto Dias ${ }^{2}$, Arthur Albuquerque Barros ${ }^{2}$, Rogério Luiz de Araújo Vian ${ }^{3}$, Pedro Miguel \\ Nunes $^{3}$, Claudiane da Silva Maia do Carmo ${ }^{4,5}$, Hélcio Tadeu Ribeiro ${ }^{6}$
}

${ }^{1}$ Unorp-University Center North Paulista-São José do Rio Preto-SP, Brazil, ${ }^{2}$ Unipos, São José do Rio Preto SP, Brazil, ${ }^{3}$ Santa Casa Hospital, Bucomaxillo Facial Traumatology Center, Ribeirão Preto SP, Brazil, ${ }^{4}$ IMMNES-Implantology Center-Macapá AP, Brazil, ${ }^{5}$ GOE-Minor Oral-Macapá AP, Brazil, ${ }^{6}$ Medical School of Ribeirão Preto-FMRP-USP, São Paulo, Brazil

\begin{abstract}
Introduction: Facial deformities have always attracted the attention of surgeons, and the most prominent is the so-called mandibular prognathism. It is a fact that the stability of any osteotomy of the mandibular branch is affected by the amount of retrusion, the fixation method, and the growth. Objective: The objective of the present study was to evaluate radiographically the variations of pharyngeal airspace, facial height, mandibular length and gonial angle in patients with Class III dento-skeletal deformity submitted to vertical osteotomy of the mandibular branch for indentation. Methods: Analysis of Teleradiographs done before and after Jaw Vertical Osteotomy of 39 patients (20 females and 19 males). In the present retrospective study, we evaluated quantitatively lateral cephalometric radiographs of patients of both genders, who needed to undergo vertical osteotomy of the mandibular branch to correct dento-skeletal deformity of the Class III type, whose purpose was to mandibular retreat. Results: There were mandibular retreatments with a decrease in mandibular length (100\%) with a change in the amount of indentation in millimeters with an amplitude of $2 \mathrm{~mm}$ to $22 \mathrm{~mm}$ and linear (23.1\%) or rotational movement (time: $30.8 \%$; counterclockwise: $44 \%$ ). The cases submitted to Mandibular Intraoral Vertical Osteotomy showed a reduction of the Gonial Angle in 13 cases. The parametric linear regression test revealed for all variables that there was no significant statistical difference between the SN_pre and SN_post variables; AF_pre and AF_post; CM_pre and CM_post; EA_pre and EA_post, and between AG_pre and AG_post, with p<0.05. Conclusion: After evaluating radiographically the pharyngeal airspace, facial height, mandibular length, and gonial angle, it was analyzed that there were mandibular retreatments with decreased mandibular length with a change in the amount of indentation and linear or rotational movement.
\end{abstract}

Key Words: Osteotomy, Radiography, Jaw, Rear airspace, Angiography, Mandibular length, Face height

\section{Introduction}

The facial deformities have always attracted the attention of surgeons, and the one that stands out most is the so-called mandibular prognathism, due to its incidence and the functional, aesthetic and psychological problems that its patients present $[1,2]$.

Deformities can be defined as changes in the development of facial bones, especially of the maxilla and mandible, and may cause changes in other structures, organs, and systems, such as the airways [2,3].

Since the nineteenth century, several osteotomies in the mandible were described [3]. The first osteotomy was described by Hullihen and consisted of a cut in the body of the mandible in order to close an open bite, which was a consequence of a cicatricial retraction of a burn in the neck [3].

Another proposed technique was a resection of the condyle $[3,4]$. Later Kostecka diffused the Osteotomy of the Colony of the Condyle realized blindly with a Mountain of Gigli and Smith and Johnson described to it with extraoral access [3]. Castro proposed a condyle osteotomy without bone resection to increase the area of bone contact and he called it "Modified osteoplasty of the mandibular ramus" [3].

Moreover, another technique proposed was the Horizontal Osteotomy of the Branch. This was performed both by extraoral and blind access with the use of a Serra de Gigli [4-6]. Ernst proposed intra-oral access. Other authors have also contributed to the evolution of the technique [7-9].

The Oblique Branch Osteotomy was proposed by Schaefer and Robinson modified it $[10,11]$. The Vertical Osteotomies of the Branch were proposed by Dingman and Letterman, performing a vertical osteotomy of the posterior branch to the mandibular foramen with decortication of the bone, causing greater bone contact [12]. This technique was improved by Converse. Trauner and Obwergeser described an inverted Losteotomy [13]. Cryer proposed Mandibular Angle Osteotomy without much acceptance [14].

It is believed that mandibular body osteotomy was first published by Blair and Dingman performed it in two stages. Converse and Shapiro proposed the realization of this technique in surgical time and by intra-oral access [15].

However, the Sagittal Osteotomy of the Branch would have been published, initially, by Perthes that made it by extraoral access [16]. It was widely accepted when Obwergeser published articles proposing its achievement by intra-oral access with a greater area of bone contact, allowing a faster and safer consolidation. Dal Pont proposed some modest modifications making the technique more versatile and safe in relation to complications [17].

Corresponding author: Dr. Idiberto José Zotarelli Filho, Unipos, Post Graduate and Continuing Education, Street Ipiranga, 3460,

São José do Rio Preto SP, 15020-040, Brazil, Tel: +55 (17) 8166-6537; E-mail: scientificresearch@unipos.com.br 


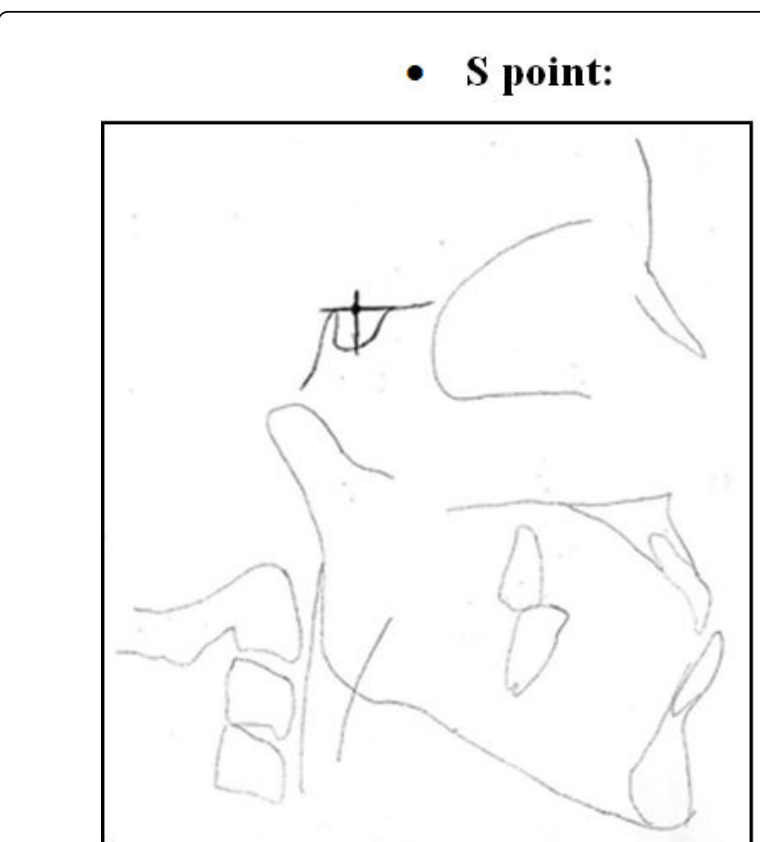

Figure 1. The $S$ point is defined by the intersection of two perpendicular lines, where one line marks the largest width of the Túrcica saddle and the other line leaves the deepest area of the Túrcica saddle.

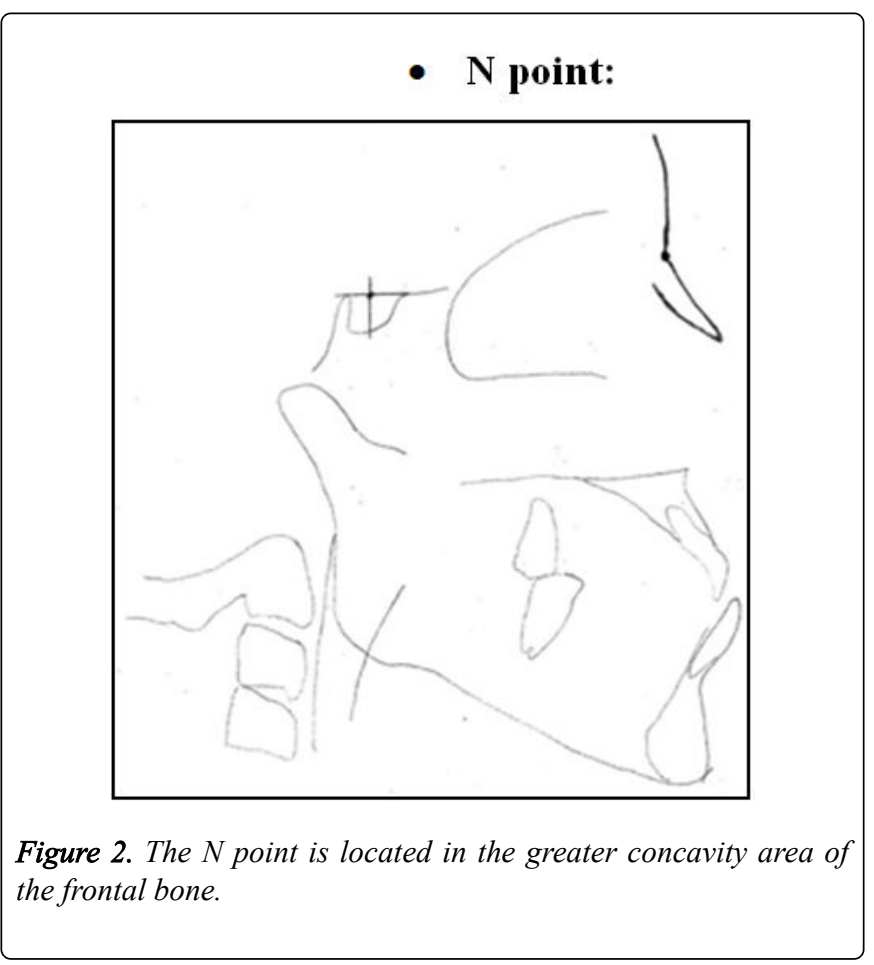

It is a fact that the stability of any osteotomy of the mandibular branch is affected by the amount of retrusion, the fixation method and the growth [6]. Vertical Osteotomy has some advantages over Sagittal Osteotomy, being: low incidence of injury or damage to the inferior alveolar nerve, technical simplicity, reduced surgical time, the possibility of repositioning the condyle and the proximal segment postoperatively, significant improvement of the symptoms of Temporomandibular Joint Dysfunction [18].
- GN point:

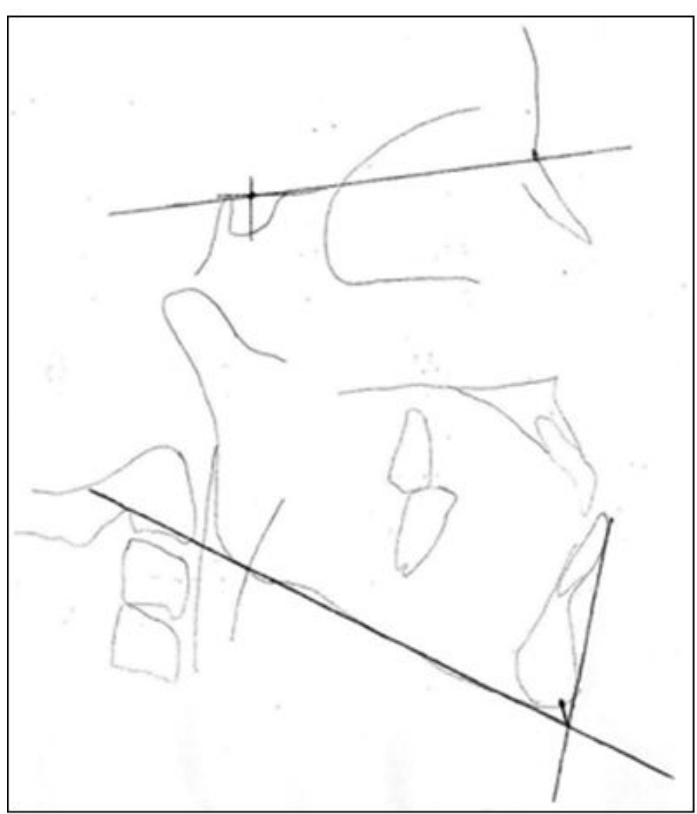

Figure 3. The GN point is located by the bisector formed at the intersection of the line running parallel to the lower border of the mandible and by a line that comes out vertically tangential to the vestibular face of the lower incisor and the anteriormost portion of the mentum.

\section{- GO point:}

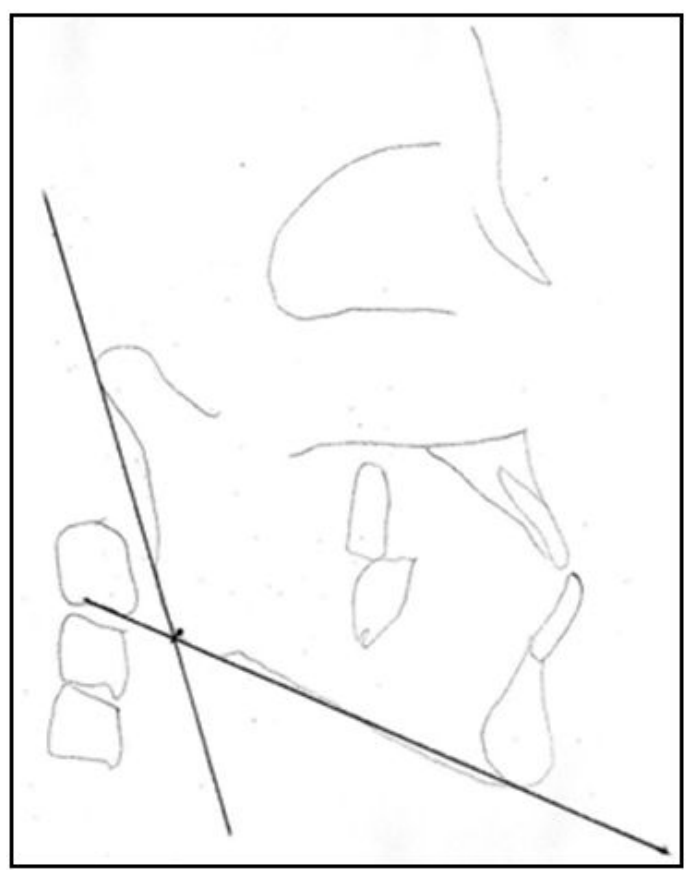

Figure 4. The GO point is located by the bisector formed by the intersection of the lines running parallel to the posterior border of the mandible and by the line running through the lower edge of the mandible body.

Therefore, the objective of the present study was to evaluate radiographically the variations of pharyngeal 
airspace, facial height, mandibular length and gonial angle in patients with Class III dento-skeletal deformity submitted to vertical osteotomy of the mandibular branch for indentation.

\section{Study Design and Methods}

The cephalograms made before and after the Vertical Jaw Osteotomy of 39 patients (20 females and 19 males) were analyzed. In the present retrospective study, we evaluated quantitatively lateral cephalometric radiographs of patients of both genders, who needed to undergo vertical osteotomy of the mandibular branch to correct to-skeletal deformity of the Class III type, whose purpose was to mandibular retreat.

For the aforementioned evaluation, radiographs were used referring to two periods: 1. preoperative (performed prior to the surgical procedure); 2. Postoperative (six months after surgery). Next, the cephalometric points of interest and the linear and angular measurements that were obtained from these points were described. The present study was informed and approved by the research ethics committee.

\section{Cephalometric Points}

With the help of a millimeter ruler of $20 \mathrm{~cm}$, a pencil (graphite $\mathrm{n}^{\mathrm{o}} 0.5$ ), a square and an angle protractor were identified 5 cephalometric points, 4 linear and 1 angular measurements, which were described in detail later. All measurements were performed by the same experienced examiner and always using the same material.

Points of interest were analyzed by Point S (Figure 1), Point N (Figure 2), Point GN (Figure 3), Point GO (Figure 4), Point PG (Figure 5), Point AP (Figure 6).

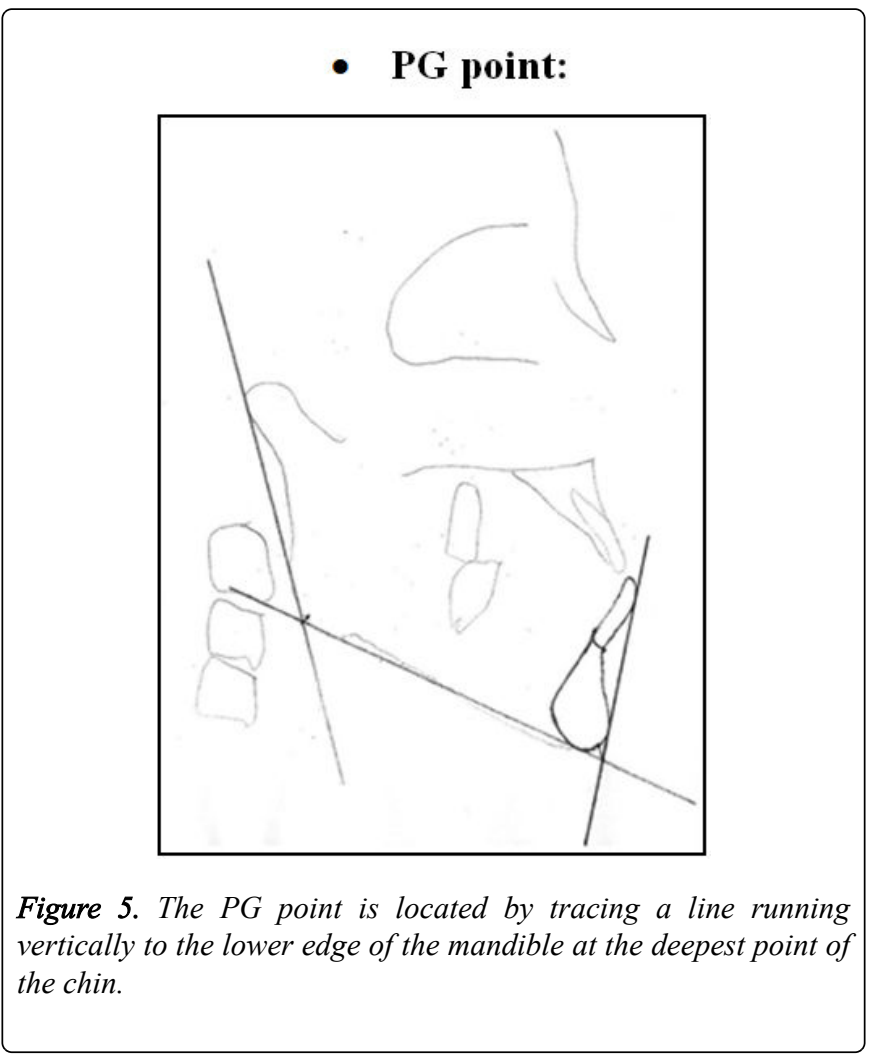

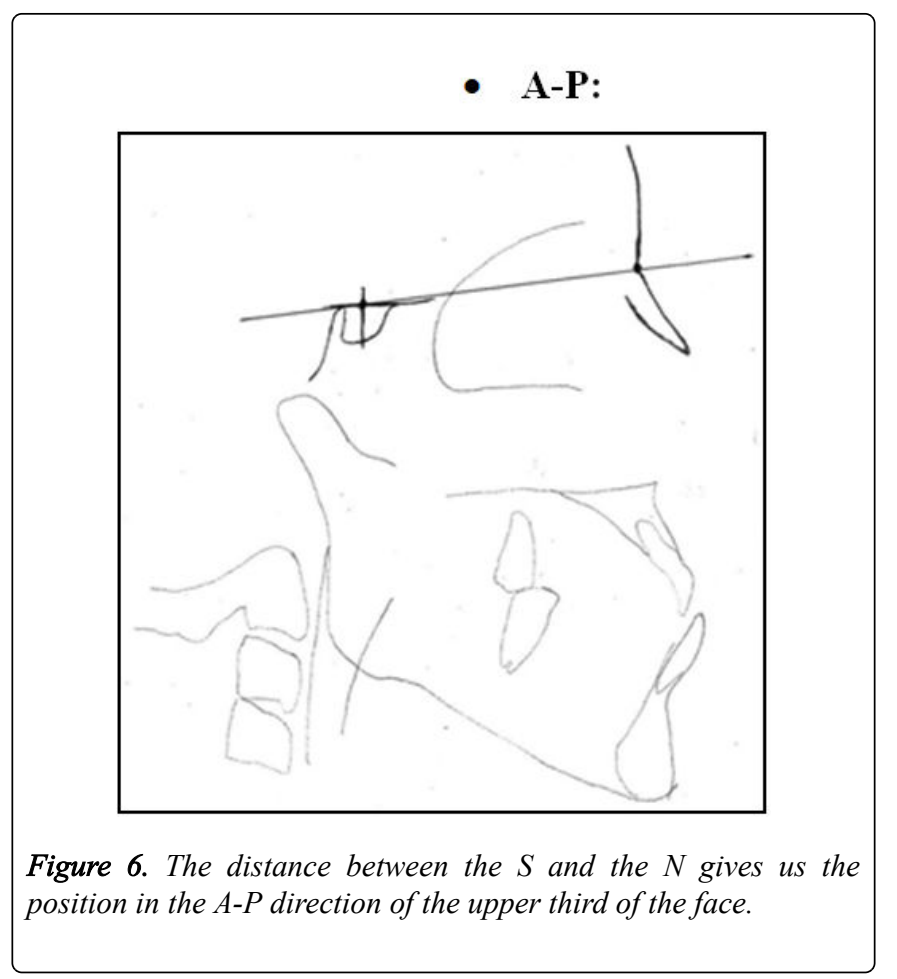

\section{Cephalometric Measurements}

\section{Linear}

The linear measures of interest were Facial Height (N-GN) (Figure 7), Mandibular Length (GO-GN) (Figure 8), and Pharyngeal air space (PAS) (Figure 9).

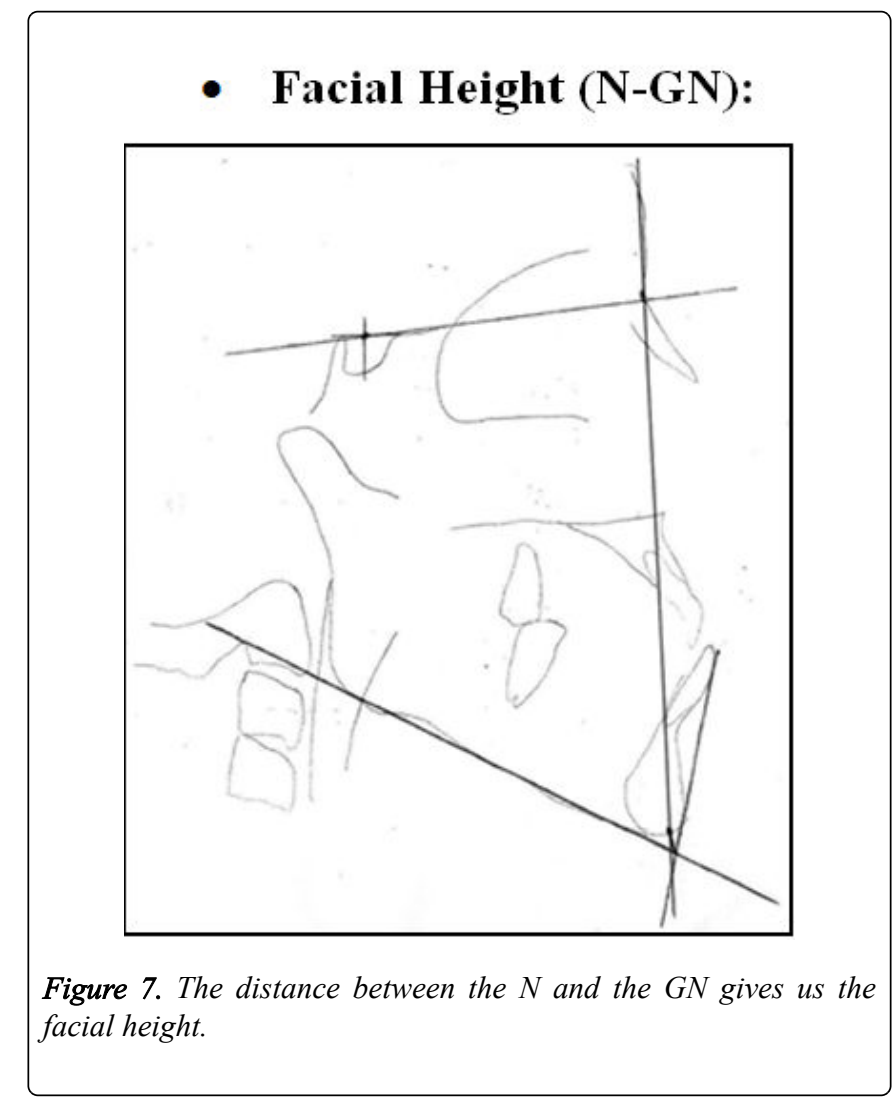




\section{- Mandibular Length (GO-GN):}

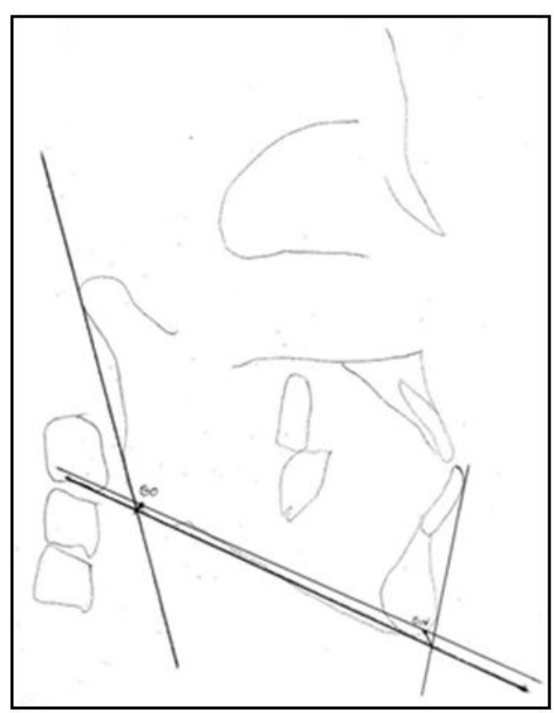

Figure 8. The distance between the GO and the GN gives us the mandibular length.

\section{- Pharyngeal airspace (PAS):}

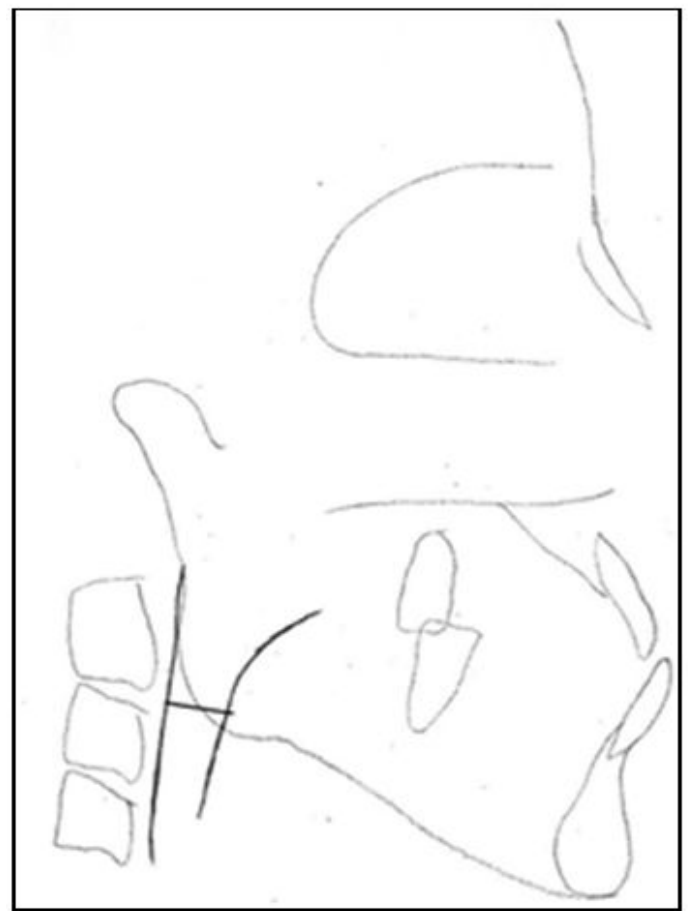

Figure 9. The pharyngeal airspace is measured by drawing a line between the $G O$ and $P G$ points and the measurement is made from the dorsum of the tongue to the posterior wall of the pharynx.

\section{Angular}

The angular measure of interest was GO (Figure 10).
- GO:

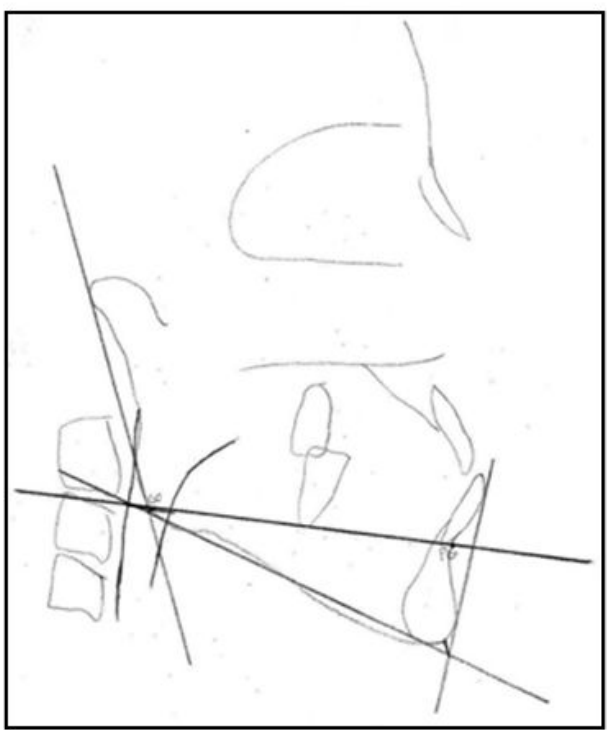

Figure 10. The gonial angle is located by the bisector formed by the intersection of the lines running parallel to the posterior border of the mandible and by the line running through the lower edge of the jaw body.

\section{Statistical Analysis}

The data were tabulated and submitted to statistical analysis using the Minitab 19 software. Descriptive statistical analysis was performed to obtain values of mean, standard deviation, median and interquartile range, as well as Anderson-Darling (AD), with $\mathrm{p}>0.10$ as normal, and linear regression analysis between the variables of the present study, with $p<0.05$ without statistical significance.

\section{Results}

As a general result, we found the following changes: there were mandibular retreatments with a decrease in mandibular length $(100 \%)$ with a change in the amount of recoil in millimeters with an amplitude of $2 \mathrm{~mm}$ to $22 \mathrm{~mm}$ and a linear (23.1\%) or rotational (hour: $30.8 \%$, counterclockwise: $44 \%$ ).

In the universe of cases submitted to Mandibular Vertical Intraoral Osteotomy, 38 patients, there was a reduction of Gonial Angle in 13 cases, an increase of this angle in 19 cases and in 6 cases there was no alteration.

In addition, after statistical analysis of normality, most of the variables presented gaussian (normal) behavior, therefore, followed by a parametric test between the variables (Figure 11). Figure 12 shows the variation of mean values, standard deviations, medians and interquartile ranges by means of the match between SN_pre and SN_post variables; AF pre and AF_post; $\mathrm{CM}$ _pre and $\mathrm{CM}$ _post; EA_pre and EA_post, and between AG_pre and AG_post.

The parametric linear regression test revealed for all variables that there was no significant statistical difference between the variables: SN_pre and SN_post; AF_pre and 
AF_post; $C M \_$pre and CM_post; EA_pre and EA_post and between $A G \_$pre and $A G \_$post, with $\mathrm{p}<0.05$ (Figure 13).

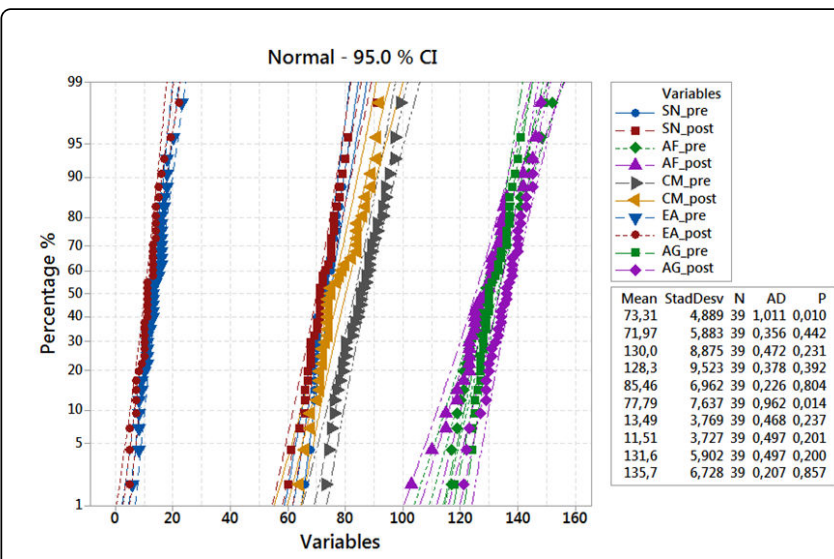

Figure 11. Normality test with $p>0.10$ for parametric analysis.

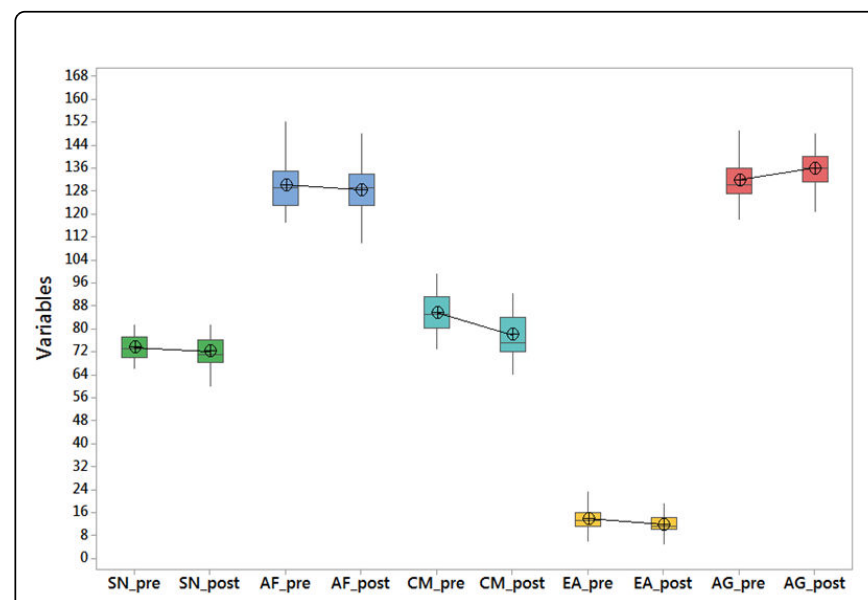

Figure 12. Box-Plot model graph showing the mean, standard deviation, median and interquartile range values of each variable.

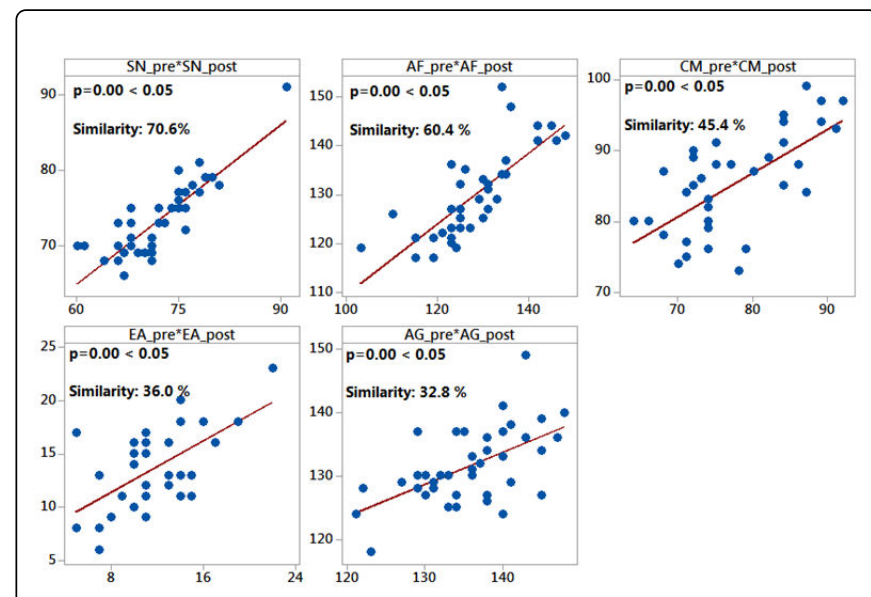

Figure 13. Linear regression analysis between each pair of continuous variables, showing similarity values in percentage between them and with p-value $<0.05$ for the non-significant test.

\section{Discussion}

The most commonly used techniques for correction of Class III malocclusion are Intraoral Vertical Ramus Osteotomy
(IVRO) and Bilateral Sagittal Split Osteotomy (BSSO) $[18,19]$.

In this context, Koichiro Ueki, concluded that an anteroinferior displacement of the condyle with medial rotation occurs in the vertical, and Martin Ritzau reported that the fixation of the posterior fragment does not influence the condylar position [17,20]. In his article, Ritzau reports anterior and inferior displacement of the condyle that in a period of one year almost completely returned the preoperative position.

Other advantages of Vertical Osteotomy are that it does not require rigid internal fixation, it allows the alteration of the gonial angle, increase of the thickness of the masseter muscle and in the electromyographic activity of the masseter and temporalis muscles $[1,2]$ and there is still a shorter recovery time and a rapid improvement of bite force when compared to Sagittal Osteotomy $[21,22]$. However, the disadvantages are intermaxillary block and there are reports of avascular necrosis of the condyle [23].

Regarding Temporomandibular Joint Dysfunction, an experiment was performed in dogs, proving, histologically, that the Vertical Osteotomy promotes a return of the bone and cartilaginous structures to a condition of normality through a lower and anterior displacement of the condyle, which leads to an increased joint space $[1,24]$.

According to Hwang Soonshin [25], Vertical Osteotomy causes a posterior inferior displacement of the hyoid bone immediately after surgery. Over time, it returns, almost entirely, to its original position. But the same does not happen with the tongue that invades the posterior airspace and does not return to its original position.

In addition, Ju Hung Pan [18] Sagittal Osteotomy presented over time a technical evolution aiming to improve bone contact and allowing greater stability, faster recovery, reduction of condylar torque and minimizing the need for the use of Fixation Intermaxillary. These are the advantages of this technique. Also, in the sagittal, in the immediate postoperative period, there is an increase in the angle of the long condylar axis, which decreases with time, and lateral rotation of the condyle [2].

Other authors observed that patients submitted to BSSO had a greater recidivation of the Sella-Nasio-Ponto B angle with greater anterior movement of Pogonium and ment than those submitted to IVRO [3].

Yoshioka et al. [6] showed that, in the immediate postoperative period, patients submitted to IVRO had a modification of Pogonium and of Point B more inferiorly and later than patients submitted to BSSO, but after one year, there was no difference in skeletal stability between techniques.

There is a strong relationship between the hourly displacement of the branch during surgery and the anterior displacement of Pogonium during the post-surgical phase. In IVRO, Kitahara et al. [5] observed that there is an hourly rotation of the proximal segment, in the sagittal plane. Pan et al. [18] reported that after IVRO there is an increase in intergonial width. 
Current techniques, sagittal and vertical, improve occlusion, function, and aesthetics due to the change in the position of the mandible, hyoid bone and tongue (Hwang Soonshin), which may cause Posterior Airspace Narrowing (PAS) and, therefore, to give rise to Obstructive Sleep Apnea Syndrome (OSAS) [2,25-29]. Class III patients have increased SBP preoperatively when compared to control patients, and show important changes immediately after surgery [5].

Riley et al. [30] published an article in which he defined that PAS is the measurement between the base of the tongue and the posterior wall of the pharynx. This measure is obtained by drawing a line connecting point $\mathrm{B}$ to point $\mathrm{GO}$ extending to the posterior wall of the pharynx, whose value rotates around $11.0 \mathrm{~mm}$. He used polysomnography and cephalometry data for the analysis of patients with OSAS.

OSAS is a sleep disorder caused by the narrowing and obstruction of the pharyngeal space during sleep and occurs in the oropharynx or velopharynx, having been associated with snoring and apnea, having as symptoms daytime sleepiness, snoring, airway obstruction, and hypoxia during sleep [2].

Furthermore, there are genetic and environmental factors that influence OSAS such as obesity, short or retruded jaw, macroglossia or long uvula, airway shape, age and ethnic factors [1]. OSAS is considered one of the risk factors for arterial hypertension, myocardial ischemia, cerebrovascular disease and traffic accidents [1,2,5].

The study of the change in SBP is done by means of radiographic images (cephalometric analysis [26,27], cephalometric analysis and computed tomography $[28,29]$ or only computed tomography $[31,32]$. Some studies also use cone beam imaging to analyze the airway through programs such as Osirix and ICAT Vision and to assess changes in pharyngeal airspace, provided the exams are performed on the same equipment. [33] Some authors report that mandibular retreat has decreased airspace [34] Others report that advancement leads to increased airspace and others report no change [21].

In order to prevent the development of OSAS after mandibular retreatment, it is important to evaluate the risks and plan the surgery, because in the study the effects on craniofacial and pharyngeal morphology are investigated [35]. Class III malocclusion leads to the mandibular protrusion, causing distortion and prominence in the lower third of the face, poor masticatory function and psychological problems [36]. The gonial angle is formed by a line that tangential the posterior border of the mandibular branch and another line running along the lower border of the mandibular body [34].

Thus, both the Vertical Osteotomy and the Sagittal Osteotomy promote a change in the Gonial Angle, but there is no predominance of one technique over the other. Many studies have shown that mandibular osteotomy produces changes in the skeleton and soft tissues, including pharyngeal airspace (PAS) [9,10]. Yoshioka et al. [6] conclude in their study that there are changes over time in the distal and proximal segments between the vertical osteotomy and the sagittal osteotomy.

In this context, Abdelrahman et al. (12 men and 18 women with a mean age of 24.4 years) divided into three groups,
Group A: 17 patients submitted to only sagittal osteotomy (9 men and 8 women), Group B: 7 patients undergoing bimaxillary advancement (4 Le Fort I and Sagittal cases and 3 Le Fort I and Vertical cases) and Group C: 6 patients submitted to vertical osteotomy (1 man and 5 women). He reports that the groups submitted only to IVRO and BSSO for retreatment had a narrowing of the SBP and the same did not occur in the bimaxillary advancement. Their analyzes were performed using lateral radiographs [37].

The lateral standard cephalometric radiographs have the advantage of ease of reproduction, simplicity, low cost and the possibility of comparison with other studies and we can still measure the movement of the soft tissue point of the posterior wall of the pharynx $[17,20,23,24,37,38]$. The SBP should be included in the predictive to avoid the occurrence of OSAS after the mandibular retreat [4]. Thus, Muto et al. [4] report that if the regression mathematical equation is applied, which is: 66-104) where the PAS-TP distance was calculated as, in which preoperative PAS-TP, postoperative C3-Me, operative C3-Me correctly, the AP dimension of the postoperative SBP will decrease. If it does not diminish it is because a change of the position of the head occurred, after performing the surgery, changing the length of $\mathrm{C} 3$ to $\mathrm{Me}$.

There is controversy in the literature if there is a change in SBP after surgery for mandibular recoil: some studies show a decrease in anterior-posterior SBP and others show that there is no change when comparing preoperative and postoperative cephalograms [9-15, 23].

The position of the head influences the A-P dimension of the PAS, a change of 10 degrees changes the A-P dimension of the PAS around $4.0 \mathrm{~mm}$ [16]. Some surgeons, in several studies, report no change in SBP [9,11-15]. However, some studies report that SBP decreases in the immediate postoperative period, but over time this decrease does not persist $[25,39]$.

If the preoperative and postoperative cephalometric radiographs are performed with the same head position and there is $10 \mathrm{~mm}$ mandibular recoil, the anteroposterior dimension of the SBP will decrease by about $4.0 \mathrm{~mm}[4,20]$. Some authors, such as Riley et al, report cases of OSA following vertical osteotomy [30].

In the cases of OSAS, some articles [24,37] report different values of SBP due to the fact that the different position of the head at the time of the preoperative and postoperative radiographs make it difficult to establish minimum values between SBP and OSAS. Therefore, the position of the head should be standardized in order to be the same in the preoperative and postoperative periods [19].

Cephalometry is not the best method to evaluate changes in SBP, since this test is two-dimensional and does not allow a dynamic evaluation of the changes that have occurred, giving preference to Tomography Cone Beam that is more accurate [40]. During life, the gonial angle changes in height and length, influenced by race and sex $[22,35,36,41]$.

Gonial angle changes in the immediate postoperative period, but in the tissue remodeling phase, it approaches values close to the preoperative period. The reason for this is in the shape of the cut that in the vertical osteotomy is 
perpendicular to the lateral surface of the mandibular branch while in the sagittal the cut is sagittally oriented $[18,19,42]$.

\section{Conclusion}

After radiographically evaluating pharyngeal airspace, facial height, mandibular length, and gonial angle, we analyzed mandibular retreatment with mandibular length decrease with a change in the amount of indentation and linear or rotational movement. The cases submitted to intraoral mandibular vertical osteotomy showed an increase of the Gonial Angle in most cases.

\section{Competing Interests}

The authors declare that they have no competing interests.

\section{Acknowledgement}

We appreciate greatly the UNIPOS graduate for support and also UNORP of Sao Jose do Rio Preto/SP for the support.

\section{References}

1. Truong MK, He P, Adeeb N, Oskouian RJ, Tubbs RS, et al. Clinical anatomy and significance of the retromolar foramina and their canals: a literature review. Cureus. 2017; 9: e1781.

2. Pluijmers BI, van de Lande LS, Caron CJJM, Wolvius EB, Dunaway DJ, et al. Part 2: Is the maxillary canting and its surgical correction in patients with CFM correlated to the mandibular deformity? Journal of Cranio-Maxillofacial Surgery. 2018; 46: 1436-1440.

3. Bendrihem R, Vacher C, Fohlen A, Pelage JP. Anatomic basis of Le Fort 1 impaction osteotomy: a radiological study. Surgical and Radiologic Anatomy. 2017; 39: 1209-1214.

4. Muto T, Yamazaki A, Takeda S, Yasunori S. Accuracy of predicting the pharyngeal space on the cephalogram after mandibular setback surgery. American Association of Oral and Maxillofacial Surgeons. 2008; 66: 1013.

5. Kitahara T, Yoshihiro H, Emiko I, Ichiro T. Changes in pharyngeal airway space and hyoid bone position after mandibular setback surgery for skeletal Class III jaw deformity in Japanese Women. American Journal of Orthodontics and Dentofacial Orthopedics. 2010; 138: 708-709.

6. Yoshioka I, Khanal A, Kazuhiro T, Akihiso H, Norihiko F, et al. Vertical ramus versus sagittal split osteotomies. comparision of stability after mandibular setback. American Association of Oral and Maxillofacial Surgeons. 2007; 66: 1138-1144.

7. Ghali GE, Silkes JW. Intraoral vertical ramus osteotomy as the preferred treatment for mandibular prognatism. Journal of Oral and Maxillofacial Surgery. 2000; 58: 313-315.

8. Tornes K. Osteotomy length and postoperative stability in vertical subcondylar ramus osteotomy. Acta Odontologica Scandinavica. 1989; 47: 81-88.

9. Athanasiou AE, Toutountzakis N, Mavreas D, Ritzau M, Wenzel A. Alterations of hyoid position and pharyngeal depth and their relationship after surgical correction of mandibular prognatism. American Journal of Orthodontics and Dentofacial Orthopedics. 1991; 100: 259-265.

10. Kawakami M, Yamamoto K, Fujimoto M, Ohgi K, Inoue M, et al. Changes in tongue and hyoid positions, and posterior airway space following mandibular setback surgery. Journal of CranioMaxillofacial Surgery. 2005; 33: 107-110.

11. Enacar A, Aksoy AU, Sencift Y, Haydar B, Aras K. Changes in hypopharyngeal airway space and in tongue and hyoid bone positions after the surgical correction of mandibular prognatism. The
International Journal of Adult Orthodontics and Orthognathic Surgery. 1994; 9: 285-290.

12. Achilleos S, Krogstad O, Lyberg T. Surgical mandibular setback and changes in uvuloglossopharyngeal morphology and head posture. A short- and long term-cephalometric study in males. European Journal of Orthodontics. 2000; 22: 383-394.

13. Tselnik M, Pogrel MA. Assessment of the pharyngeal airway space after mandibular surgery setback. Journal of Oral and Maxillofacial Surgery. 2000; 58: 282-285.

14. Samman N, Tang SS, Xia J. Cephalometric study of the upper airway in surgically corrected Class III skeletal deformity. The International Journal of Adult Orthodontics and Orthognathic Surgery. 2002; 17: 180-190.

15. Saito K. Long-term changes in pharyngeal airway morphology after mandibular setback. American Journal of Orthodontics and Dentofacial Orthopedics. 2004; 125: 556-561.

16. Muto T, Takeda S, Kanazawa M, Yamazaki A, Fujiwara Y, et al. The effect of head posture on the pharyngeal airway space (PAS). International Journal of Oral and Maxillofacial Surgery. 2002; 31: 579.

17. Makoc S, Usumez S, Nur M, Donaghy CE. Reproducibility of airway dimension and tongue and hyoid positions on lateral cephalograms. American Journal of Orthodontics and Dentofacial Orthopedics. 2005; 124: 513-516.

18. Pan JH, Lee JJ, Lin HY, Chen YJ, Jane Yao CC, et al. Transverse and sagittal angulations of proximal segment after sagittal split and vertical ramus osteotomies and their influence on the stability of distal segment. Journal of the Formosan Medical Association. 2013; 112: 244-252.

19. Reyneke JP, Ferretti C. The Bilateral sagittal split mandibular ramus osteotomy. Atlas of the Oral and Maxillofacial Surgery Clinics of North America. 2016; 24: 27-36.

20. Riley RW, Powell NB, Guilleminault C, Ware W. Obstructive sleep syndrome after surgery for mandibular prognatism. Journal of Oral and Maxillofacial Surgery. 1987; 45: 450-453.

21. Ohm E, Silness J. Size of the mandibular jaw angle related to age, tooth retention and gender. Journal of Oral Rehabilitation. 1999; 26: 883-891.

22. Kim YG, OH SH. Effect of mandibular setback surgery on occlusal force. Journal of oral and maxillofacial surgery Copenhage. 2010; 68: 2221-2223.

23. Endo S, Mataki S, Kurosaki N. Cephalometric evaluation of craniofacial and upper airway structures airway in Japanese patiens with obstructive sleep apneia. Journal of Medical and Dental Sciences. 2003; 50: 109-120.

24. Hui DSC, Ko FWS, Chu ASY, Fok JP, Chan MC, et al. Cephalometric assessment of craniofacial morphology in Chinese patiens with obstructive sleep apneia. Respiratory Medicine. 2003; 97: 640-646.

25. Hwanga S, Chungb CJ, Choic YJ, Huh JK, Kim KH. Changes of hyoid, tongue and pharyngeal airway after mandibular setback surgery by intraoral vertical ramus osteotomy. The Angle Orthodontist. 2010; 80: 302.

26. Pereira Filho VA, Castro-Silva LM, Moraes M, Gabrielli MF, Campos JA, et al. Cephalometric evaluation of pharyngeal airway space changes in Class III patients undergoing orthognatic surgery. Journal of Oral and Maxillofacial Surgery. 2011; 69: 409- 415.

27. Sears CR, Miller Aj, Chang MK, Huang JC, Lee JS. Comparision of pharyngeal airway changes on plain radiography and cone-beam computed tomography after orthognatic surgery. Journal of Oral and Maxillofacial Surgery. 2011; 69: 385-394.

28. Souza Carvalho ACG, Magro Filho O, Garcia Junior, Araujo PM, Nogueira RL. Cephalometric and three-dimensional assessment of superior posterior airway space after maxillomandibular advancement. International Journal of Oral and Maxillofacial Surgery. 2012; 41: 1102-1111.

29. Degerliyurt K, Ueki K, Hashiba Y, Marukawa K, Nakagawa $\mathrm{K}$, et al. A comparative $\mathrm{CT}$ evaluation of pharyngeal airway changes 
in Class III patiens receiving bimaxillary surgery or mandibular setback surgery. Oral Surgery, Oral Medicine, Oral Pathology, Oral Radiology, and Endodontics. 2008; 105: 495-502.

30. Riley R, Guilleminault C, Herran J, Powel N. Cephalometric analyses and flow volume loops in obstructive sleep apnea patients. Sleep. 1983; 6: 303-311.

31. Hong J, Oh KM, Kim BR, Kim YJ, Park YH. Threedimensional analysis of pharyngeal airway volume in adults with anterior position of the mandible. American Journal of Orthodontics and Dentofacial Orthopedics. 2011; 140: 161-169.

32. Gonçales ES, Duarte MAH, Palmieri C Jr, Zakhary GM, Ghali GE. Retrospective analysis of the effects of orthognatic surgery on the pharyngeal airway space. Journal of Oral and Maxillofacial Surgery. 2014; 72: 2227-2240.

33. Lee KT, Lai SS, Wu JH, Lee HE, Chen CM. Correlation between the change of gonial region and skeletal relapse after intraoral vertical ramus osteotomy for correction of mandibular prognatism. Journal of Craniofacial Surgery. 2011; 22: 818-821.

34. Hellman M. The face and teeth of man. A study of growth and position. Journal of Dental Research. 1929; 9: 179-201.

35. Ishii N, Deguchi T, Hunt NP. Craniofacial differences between Japanese female and British Caucasian females with a skeletal class III malocclusion. European Journal of Orthodontics. 2002; 24: 493-499.

36. Ngan P, Hagg U, Yiu C, Merwin D, Wei SH. Cephalometric comparisons of Chinese and Caucasian surgical class III patiens. The
International Journal of Adult Orthodontics and Orthognathic Surgery. 1997; 12: 177-188.

37. Abdelrahman TEF, Takahashi K, Tamura K, Nakao K, Hassanein $\mathrm{KMH}$, et al. Impact of different modalities to correct class iii jaw deformity on the pharyngeal airway space. Journal of Craniofacial Surgery. 2011; 22: 1598-1601.

38. Chen F, Terada K, Hua Y, Saito I. Effects of bimaxillary surgery and mandibular setback surgery on pharyngeal airway measurements in patiens with Class III skeletal deformities. Am J Ortho Dentofacial Orthop. 2007; 131: 372-376.

39. Gonçales ES. Cirurgia ortognatica- guia de orientação para portadores de deformidades faciais esqueléticas. São Paulo, SP, Santos. 2009: 2.

40. Afonso JBS. Forcas de Língua e de mordida isométricas máximas em pacientes submetidos a cirurgia ortognatica. 2014. $24 \mathrm{f}-$ Tese Faculdade de Medicina, Universidade de São Paulo, Ribeirão Preto, 2014.

41. McNamara JA. A Method of cephalometric evaluation. American Journal of Orthodontics. 1984; 86: 449-469.

42. Marsan G, Cura N, Emekli U. Changes in pharyngeal (airway) morphology in class III Turkish female patiens after mandibular setback surgery. Journal of Cranio-Maxillofacial Surgery. 2008; 36: 341-345. 